\title{
Penentuan Kelayakan Tahanan Isolasi Pada Transformator 60 MVA Di Gardu Induk 150 kV Tegal Dengan Menggunakan Indeks Polarisasi, Tangen Delta, Dan Breakdown Voltage
}

\author{
Muhamad Firdaus Robbani' ${ }^{1)}$, Dedi Nugroho' ${ }^{2}$, Gunawan ${ }^{3)}$ \\ 1,2,3) Program Studi Teknik Elektro, Fakultas Teknologi Industri, Universitas Islam Sultan Agung Semarang \\ 1,2,3) Jl. Raya Kaligawe Km.4 Po.Box 1054 Semarang 50112 \\ e-mail: firdausrobbani@std.unissula.ac.id ${ }^{1)}$, dedi.nugroho@ unissula.ac.id ${ }^{2)}$, gunawan@ unissula.ac.id ${ }^{3)}$
}

\begin{abstract}
A power transformer is electrical power equipment that works to transmit power or electrical power from high voltage to low voltage or on the contrary. In the operation of distributing electricity, the transformer can be said to be the heart of transmission and distribution. In this condition, a transformer is expected to operate optimally according to its function.. If the isolation state of the transformer deteriorates, it can have an impact on operating failure and the most fatal of which is that the transformer is damaged which can cause disturbances in the electrical system. To overcome this, it is necessary to analyze the isolation resistance.

This study analyzes the isolation resistance on a transformer using the polarization index, tangent delta and oil breakdown voltage methods to determine the quality of the isolation on the transformer. This study took data at the $150 \mathrm{kV}$ substation Tegal. The data used include polarization index test data, tangent delta data, bottom oil breakdown voltage test data, and OLTC oil. After the data is obtained, then calculations and analyzes are carried out to obtain accurate results.

The test results at the $150 \mathrm{kV}$ substation Tegal showed the polarization index value with the lowest IP of 1.26 in the primaryground section and the highest IP of 1.97 in the primary-secondary section is still in good condition. The results of the tangent delta test are still in good condition, only in the CHT mode experienced a negative delta tan deterioration of $0.07 \%$. The result of the average oil test is still suitable for use with $69.9 \mathrm{kV}$ of bottom oil and $53.3 \mathrm{kV}$ of OLTC oil.
\end{abstract}

Keywords : power transformer, substation, isolation resistance.

\begin{abstract}
ABSTRAK
Transformator tenaga suatu peralatan tegangan tinggi yang berfungsi sebagai penyalur daya listrik dari tegangan tinggi ke tegangan rendah atau dari tegangan rendah ke tegangan tinggi. Apabila transformator keadaan isolasinya mengalami pemburukan maka bisa berdampak mengalami kegagalan operasi dan yang paling fatal adalah transformator mengalami kerusakan yang bisa menyebabkan gangguan sistem kelistrikan. Untuk mengatasi hal tersebut maka perlu dilakukan pengujian tahanan isolasi.

Pengujian ini dilakukan menggunakan metode indeks polarisasi,tangen delta, dan breakdown voltage berguna untuk mengetahui kelayakan tahanan isolasi yang ada di transformator. Penggunaan metode ini adalah yang paling akurat dan efektif untuk mengetahui kelayakan tahanan isolasi pada transformator di gardu induk-gardu induk yang ada di Indonesia. Penelitian ini mengambil data dilokasi gardu induk $150 \mathrm{kV}$ tegal. Data-data yang digunakan meliputi data pengujian indeks polarisasi,data tangen delta dan data pengujian breakdown voltage minyak bawah dan minyak OLTC. Setelah data diperoleh kemudian langkah selanjutnya adalah menghitung dan menganalisis untuk mendapatkan hasil yang akurat.

Hasil pengujian pada gardu induk $150 \mathrm{kV}$ Tegal menunjukkan nilai indeks polarisasi dengan IP terendah 1,26 pada ruas primer dan IP tertinggi 1,97 pada ruas primer-sekunder masih dalam kondisi baik. Hasil pengujian delta tangen masih dalam kondisi baik, hanya pada mode CHT mengalami penurunan delta tan negatif sebesar 0,07\%. Hasil pengujian oli rata-rata masih layak digunakan dengan oli dasar 69,9 kV dan oli OLTC 53,3 kV.
\end{abstract}

Kata kunci : transformator tenaga,gardu induk, tahanan isolasi.

\section{Pendahuluan}

$\mathrm{Z}$ aman modern sekarang ini, kebutuhan akan tenaga listrik telah menjadi kebutuhan primer baik di kota yang berbasis besar maupun kota yang berbasis kecil. PT.PLN (Persero) adalah satu-satunya perusahaan yang bergerak di bidang penyaluran tenaga listrik harus mampu menjaga ketersediaan stabilitas listrik bahkan sampai kepelosok wilayah indonesia. Menjaga agar listrik tetap tersedia bisa dikerjakan dengan salah satu caranya yaitu, dengan memelihara komponen-komponen penyalur energi listrik tersebut. Yang termasuk komponen-komponen penyalur tenaga listrik yaitu ada transformator tenaga yang berfungsi untuk menyalurkan daya listrik dari tegangan yang tinggi ke tegangan yang lebih rendah atau sebaliknya dari tegangan yang rendah ke tegangan tinggi tergantung dari jenis transformatornya. Oleh karena itu transformator tenaga harus dalam keadaan baik ketika dioperasikan mengingat fungsinya yang sangat penting. Salah satu cara untuk mengetahui transfromator dalam keadaan baik atau tidak adalah dengan dilakukan pengujian transformator.

Pengujian dilakukan agar mengetahui kualitas isolasi yang ada di bagian-bagian transformator apakah dalam keadaan yang baik atau mengalami suatu masalah. Pengujian tahanan isolasi sangat penting karena untuk mencegah terjadinya arus bocor pada belitan yang dapat menyebabkan gangguan pada transformator sehingga 
dapat membuat tranformator mengalami kerusakan. Faktor-faktor yang mempengaruhi kualitas tahanan isolasi pada transformator tenaga menurun antaralain: suhu,jalur bocor pada permukaan eksternal seperti kotoran pada bushing atau isolator kotor, usia peralatan atau komponen, dan alat uji. Kualitas pada isolasi transformator tenaga bisa diperoleh dengan menggunakan hasil pengujian tahanan isolasi dengan menggunakan metode indeks polarisasi,tangen delta dan breakdown voltage, semua pengujian menggunakan metode ini termasuk pengujian tidak merusak komponen pada transformator karena pengujian ini yang digunakan oleh pln untuk mengetahui kualitas isolasi transformator.

Metode ini jauh lebih kompleks serta menyeluruh dibandingkan metode lain yang hanya menggunakan satu pengujian untuk menganalisis suatu objek. Pada prakteknya, kualitas pada isolasi menjadi buruk setelah digunakan dalam jangka waktu yang cukup lama. Memburuknya kualitas isolasi bisa ditentukan dari nilai tangen delta yang besar dan nilai tahanan isolasi yang semakin kecil. Pada Gardu Induk $150 \mathrm{kV}$ Tegal mempunyai empat transformator yang beroperasi masing-masing berkapasitas 60 MVA semua. Untuk transformator satu dan dua menghubungkan ke jaringan Gardu Induk $150 \mathrm{kV}$ Brebes dan tranformator tiga dan empat menghubungkan ke jaringan Gardu Induk $150 \mathrm{kV}$ Pemalang. Usia-usia peralatan di gardu induk $150 \mathrm{kV}$ tegal sendiri rata-rata sudah lebih dari sepuluh tahun lebih beroperasi. Masalah dalam penelitian ini adalah bagaimana mengetahui kualitas tahanan isolasi pada transformator tenaga di Gardu Induk $150 \mathrm{kV}$ Tegal yang disebabkan oleh faktor suhu,usia peralatan dan alat uji. Solusi terhadap permasalahan ini adalah maka perlu dilakukan pengujian tahanan isolasi pada transformator tenaga agar dapat diketahui kondisinya sehingga operasi kerja dari transformator dapat berjalan sesuai dengan fungsinya.

\section{TINJAUAN DAN LANDASAN TEORI}

Muhammad Syahendra anindyantoro (2017) pada penelitiannya yang berjudul "Analisa tahanan isolasi pada transformator tenaga di gardu induk wonogiri" dari hasil dari penelitian ini adalah perhitungan indeks polarisasi didapatkan nilai lebih besar dari 1,1-1,25 dalam kondisi baik, dan jika nilainya kurang dari 1,11,25 maka perlu penanganan trafo. Perhitungan delta tan untuk menilai apakah kondisi delta tangen masih baik, jika nilai delta tan lebih dari $0,5 \%$, maka delta tangen dalam kondisi buruk dan perlu dilakukan pemeriksaan lebih lanjut, bila nilainya $0,5 \%$ lebih rendah, tan delta bagus. Terakhir, pengujian oli hanya dilakukan untuk memeriksa kondisi oli pada suhu $30^{\circ} \mathrm{C}$ untuk trafo dan 38C untuk OLTC.

Tomy adi saputro (2018) pada penelitiannya yang berjudul "Analisis hasil pengujian tahanan isolasi transformator daya berdasarkan hasil uji indeks polarisasi,tangen delta, rasio tegangan, BDV (break down voltage)" Hasil dari penelitian ini merupakan hasil pengujian yang dilakukan di gardu induk Wonosari dan menghasilkan nilai indeks polarisasi kerusakan ruas tanah primer sebesar 0,95. Hasil pengujian rasio tegangan menunjukkan bahwa kondisi masih baik dengan nilai rata-rata kurang dari $0,5 \%$. Hasil uji tan delta menunjukkan bahwa terjadinya deteriorasi pada mode CL sebesar 0.83 - 1.65\%. Hasil pengujian medium oil menunjukkan kondisi yang masih baik yaitu base oil $64,5 \mathrm{kV}$ dan oltc oil 54,4 kV. Hasil pengujian di stasiun Sragen menunjukkan bahwa nilai indeks polarisasi masih baik yaitu nilai rata-rata lebih besar dari 1.1-1.25. Hasil pengujian rasio tegangan menunjukkan bahwa kondisi masih dalam keadaan baik dengan nilai rata-rata kurang dari $0,5 \%$. Hasil uji tangen delta menunjukkan penurunan delta tan negatif pada mode CL yaitu $-0,12 \%$ dan sedikit penurunan pada mode CL. 0,55\%. Hasil pengujian minyak transformator menunjukkan kondisi yang masih baik yaitu minyak bawah $86,4 \mathrm{kV}$ dan minyak oltc $85,2 \mathrm{kV}$.

Dwi Ari Wibowo (2018) dalam penelitiannya berjudul "Analisis Pengujian Isolasi Transformator Daya 60 mva pada Gardu Induk". Hasil penelitian menunjukkan bahwa semua tes dalam kondisi baik atau cukup. Menurut standar IEEE Std 286TM-2000 (R2006), nilai indeks polarisasi (IP) adalah 1,42. Nilai rata-rata faktor disipasi (DF) adalah $0,11 \%$. Hasil pengujian minyak trafo rata-rata adalah $43,3 \mathrm{kV}$.

\section{A. Transformator}

Tranformator merupakan sebuah alat magnetoelektrik yang sederhana, andal,dan efisien berfungsi merubah tegangan arus bolak-balik dari suatu tingkat ke tingkat yang lainnya. Pada umumnya, suatu transformator terdiri dari sebuah inti yang terbuat dari besi berlapis dan dua buah belitan, yaitu belitan primer dan belitan sekunder. Rasio perubahan tegangan akan bergantung dari rasio jumlah lilitan pada kedua buah belitan tersebut, dengan kata lain tegangan berbanding lurus dengan belitan. Semakin tinggi nilai tegangan maka semakin banyak belitannya.

Pada transformator ideal berlaku perbandingan seperti pada persamaan dibawah

$$
\frac{N p}{N s}=\frac{V p}{V s}=\frac{I s}{I p}
$$

\footnotetext{
Dimana :

$\mathrm{Np}=$ Banyaknya belitan pada sisi Primer

Ns = Banyaknya belitan pada sisi Sekunder

$\mathrm{Vp}=$ Tegangan pada sisi Primer

Vs $=$ Tegangan pada sisi Sekunder

Ip = Arus pada sisi Primer

Is $=$ Arus pada sisi sekunder
} 


\section{B. Pengujian Transformator}

Pengujian trafo di gardu induk merupakan rangkaian kegiatan yang bertujuan untuk memperoleh informasi mengenai kondisi trafo. Berdasarkan data yang diperoleh akan dilakukan analisis dan evaluasi yang akan menentukan tindakan selanjutnya. Secara tidak langsung pengujian ini berfungsi untuk menjaga kondisi dan memastikan bahwa trafo dapat menjalankan fungsinya dengan baik, sehingga dapat menjaga kehandalan, ketersediaan dan efisiensi dari keseluruhan sistem. Faktor yang paling berpengaruh pada peralatan listrik tegangan tinggi adalah sistem insulasi. Ada berbagai jenis isolasi pada trafo seperti: isolasi keras (padat) dan minyak isolasi (cair). Isolasi merupakan bagian yang paling vital dan sangat mempengaruhi umur suatu trafo. Pengujian transformator dibedakan menjadi dua yaitu pengujian transformator tegangan atau running dan pengujian transformator keadaan mati.

Pengujian trafo dibawah tegangan bertujuan untuk mengetahui status trafo tanpa harus mematikannya. Tes yang dilakukan meliputi:

\section{Thermovisi / Thermal Image \\ 2. Dissolve Gas analysis (DGA) \\ 3. Pengujian kualitas minyak isolasi (karakteristik) \\ 4. Pengujian Furan \\ 5. Pengujian Corrosive Sulfur \\ 6. Pengujian Partial Discharge \\ 7. Vibrasi dan Noise}

Pengujian transformator dalam keadaan offline merupakan pengujian yang dilakukan pada saat transformator dalam keadaan bebas tegangan. Pengujian dilakukan secara berkala, dalam hal ini dilakukan setiap dua tahun (dua tahun), dan mengacu pada instruksi manual pabrikan yang memproduksi trafo, dengan standar yang digunakan (IEC, CIGRE, ANSI, dll.) Dan pengalaman operasional di lapangan. Pengujian trafo yang tidak diberi energi juga dilakukan selama inspeksi kesalahan atau ketika trafo mengalami kinerja pengoperasian yang buruk.

Pengujian ini dilakukan pada komponen yang sangat penting dari transformator, seperti busing, kumparan atau belitan, pengubah tap pada beban (OLTC) dan sistem perlindungan internal transformator.

\section{Pengujian Indeks polarisasi pada transformator tenaga}

Tujuan pengukuran tahanan isolasi pada belitan adalah untuk menentukan keadaan isolasi antara dua belitan atau antara belitan dan bumi. Dengan mentransfer sumber arus searah, nilai resistansi isolasi dalam megohms akan diperoleh. Dalam hal ini, digunakan alat yang disebut Megaohm meter yang biasanya memiliki kapasitas uji 500, 1000 atau $2500 \mathrm{kV}$.
Tahanan isolasi yang diukur merupakan fungsi dari arus bocor yang melalui isolasi atau arus yang melewati jalur kebocoran pada permukaan luar. Oleh karena itu, hal ini dipengaruhi oleh faktor-faktor seperti suhu, kelembaban dan jalur kebocoran ke permukaan yang dipengaruhi oleh adanya kotoran yang menempel pada insulasi. Arus bocor tidak dapat dihindarkan, namun harus sesuai dengan syarat dan ketentuan yang telah ditentukan. Perhitungan indeks polarisasi seperti rumus di bawah ini:

$$
I P=\frac{\mathrm{R} 10}{\mathrm{R} 1}
$$

Dimana :

$$
\begin{aligned}
& \text { IP = Indeks Polarisasi } \\
& \text { R10 = Pengujian pada menit ke-10 } \\
& \text { R1 = Pengujian pada menit ke-1 }
\end{aligned}
$$

Tabel 2. 1 Standar indeks polarisasi trafo tenaga menggunakan IEEE 43-2000

\begin{tabular}{lll}
\hline Hasil pengujian & Keterangan & Rekomendasi \\
\hline$<1$ & Berbahaya & Ditindak lanjuti \\
\hline $1-1,1$ & Jelek & Ditindak lanjuti \\
\hline $1,1-1,25$ & Dipertanyakan & $\begin{array}{l}\text { Uji kadar } \\
\text { minyak,uji tan } \\
\text { delta }\end{array}$ \\
& & - \\
\hline $1,25-2$ & Baik & - \\
\hline$>2$ & Sangat baik & \\
\hline
\end{tabular}

\section{Pengujian tangen delta}

Kegagalan yang terjadi dalam pengoperasian peralatan listrik tegangan tinggi seringkali merupakan akibat dari kemunduran atau kemunduran kondisi insulasi sebagai akibat dari kegagalan yang terjadi pada bagian-bagiannya. Tan Delta atau yang sering disebut dengan loss angle atau uji faktor disipasi merupakan metode diagnostik kelistrikan yang digunakan untuk mengetahui kondisi insulasi. Jika isolasi bebas dari kesalahan atau kekurangan, maka isolasi tersebut akan menjadi kapasitif sempurna seperti penyekat antara dua elektroda pada kapasitor.

Kapasitor arus penuh akan mendahului tegangan dengan sudut $90^{\circ}$ jika memiliki sumber AC. Jika terjadi kontaminasi pada isolasi maka nilai tahanan isolasi akan berkurang dan berdampak pada arus resistif yang tinggi melalui isolasi tersebut. Isolasi bukan lagi kapasitor yang sempurna. Tegangan dan arus tidak akan berubah lebih dari $90^{\circ}$ tetapi akan bergerak kurang dari 90 o. Nilai offset $90^{\circ}$ menunjukkan tingkat kontaminasi dari insulasi.

Keadaan isolasi pada transformator dapat diprediksi dengan mengetahui hasil pengujian tangen deltanya. Dimana untuk interpretasi hasil pengujian merujuk ke aturan standar ANSI C57.12.90.

Perhitungan tangen delta menggunakan rumus dibawah ini :

Sehingga,rumus tandelta sebagai berikut :

$$
\text { Tan } \delta=\frac{P}{V^{2} \omega \mathrm{C}}
$$


Keterangan :

\begin{tabular}{|c|c|}
\hline$\delta$ & $=$ Delta \\
\hline$P$ & $=$ Daya $($ Watt $)$ \\
\hline $\mathrm{V}$ & $=$ Tegangan $($ Volt $)$ \\
\hline $\begin{array}{l}\mathrm{C} \\
\omega\end{array}$ & $\begin{array}{l}=\text { Capacitance }(\mathrm{F}) \\
=2 \pi \mathrm{f}\end{array}$ \\
\hline
\end{tabular}

Tabel 2.2 standar pengujian tan delta menggunakan ANSI C 57.12 .90

\begin{tabular}{ll}
\hline Hasil uji & Kondisi \\
\hline$\leq 0,5 \%$ & Bagus \\
\hline $0,5 \%-0,7 \%$ & Mengalami penurunan \\
\hline$\geq 1.0 \%$ & Jelek \\
\hline
\end{tabular}

\section{E. Pengujian Breakdown voltage}

Pengujian kekuatan tarik digunakan untuk melihat tahanan minyak isolasi dalam menahan tegangan. Pengujian mengacu pada IEC 60156. Pengujian dilakukan saat menguji transformator dalam keadaan mati untuk menghemat waktu. Selama pengujian ini, oli juga diganti di tangki konservator. Oli transformator menerima tegangan frekuensi dari sistem menggunakan metode penempatan dua elektroda. Jarak elektroda tergantung pada standar yang digunakan, dalam hal ini $2,5 \mathrm{~mm}$. Perhitungan kekuatan dielektrik minyak trafo menggunakan rumus berikut :

$$
\text { Erata-rata }=\frac{V b(\text { rata }- \text { rata })}{d}(k v / m m)
$$

\section{Dimana :}

$\mathrm{Vb}=$ Tegangan tembus $(\mathrm{kv})$

$\mathrm{E}=$ kekuatan dielektrik $(\mathrm{kv} / \mathrm{mm})$

$\mathrm{d}=$ jarak sela $(\mathrm{mm})$

\section{METODOLOGI}

Metode penelitian berisi tentang metode yang dipakai dalam melakukan penelitian. Pada penelitian tugas akhir ini, metode penelitian yang dilakukan oleh penulis sebagai berikut:

Dalam penelitian ini, penulis mengambil lokasi dan objek penelitian pada Gardu Induk 150 kV kebasen Tegal. Lokasi ini dipilih karena merujuk pada data primer yang ada, dikarenakan tidak semua data primer yang dibutuhkan untuk penelitian ada pada lokasi penelitian, oleh sebab itu pemilihan lokasi di pilih dengan meggunakan data yang terlengkap.

Lokasi pengambilan data-data teknis yang dibutuhkan guna penelitian ini dilakukan di UPT Purwokerto, waktu pengambilan data ini dimulai dari tanggal 6 Juli 2020 sampai 20 Juli 2020. Data-data yang digunakan untuk penelitian adalah data sekunder dari Gardu Induk $150 \mathrm{kV}$ kebasen Tegal meliputi data tahunan 2018 dan 2020 untuk nilai indeks polarisasi dan tangen delta serta data tahunan tahun 2020 untuk nilai minyak OLTC dan minyak bawah. Peneliti melakukan wawancara dengan pihak supervisory Gardu Induk 150 $\mathrm{kV}$ Tegal mengenai transformator tenaga bay 4 terutama dibagian tahanan isolasinya dan data-data pengujian tahanan isolasi terakhir kali dilakukan serta metode pengujian yang digunakan disini.

Data yang di peroleh dari Gardu Induk $150 \mathrm{kV}$ Tegal. khususnya kemudian dilakukan perhitungan menggunakan software microsoft excel. Berikut adalah data yang di peroleh dari hasil survei data:

a. Data Transformator Tenaga

b. Data indeks polarisasi pada transformator 4 tahun 2018 dan 2020 di Gardu Induk 150 kV Tegal.

c. Data tangen delta pada transformator 4 tahun 2018 dan 2020 di Gardu Induk 150 kV Tegal.

d. Data pengujian minyak bawah dan minyak oltc transformator 4 tahun 2020 di Gardu Induk 150 $\mathrm{kV}$ Tegal.

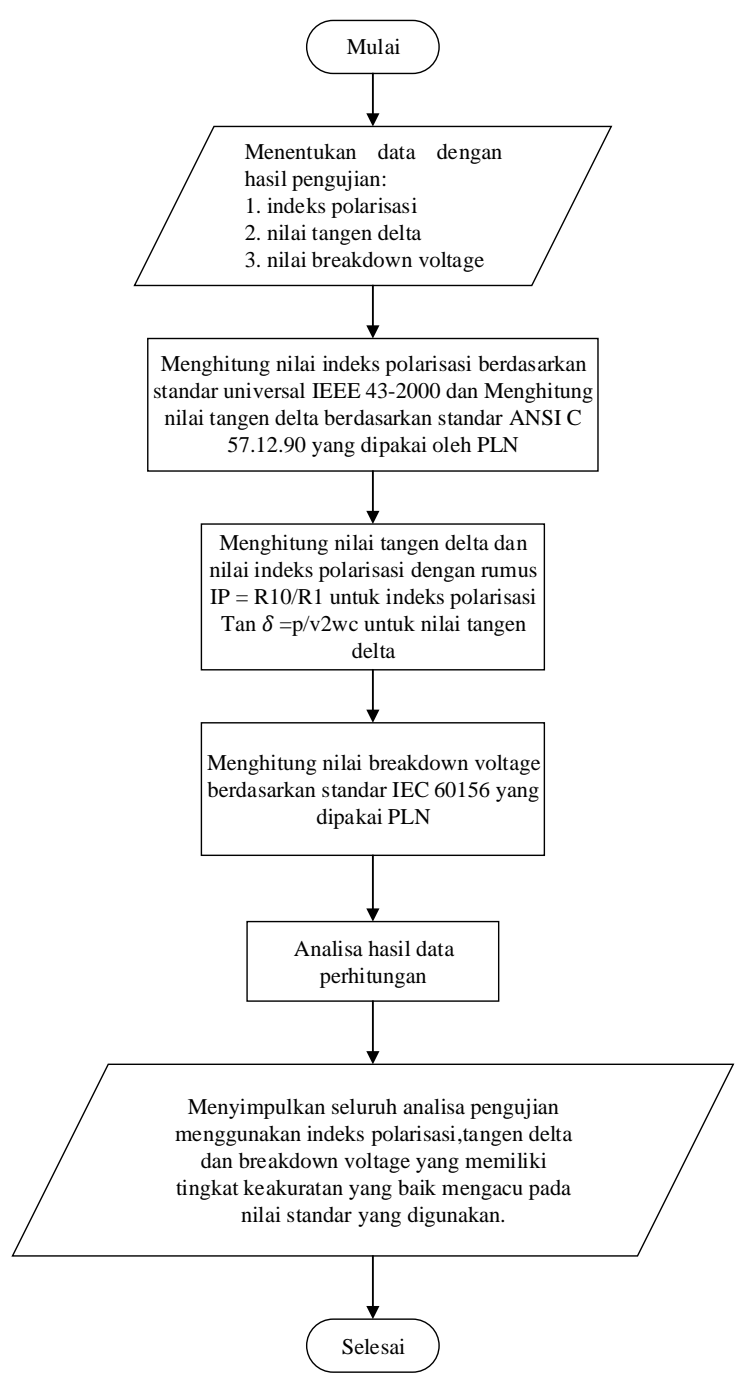

Gambar 3. 1 Diagram alir penelitian 


\section{HASIL DAN PEMBAHASAN}

\section{A. Hasil Pengujian Indeks Polarisasi tahun 2018}

Tabel 4. 1 hasil pengujian indeks polarisasi tahun 2018

\begin{tabular}{llllllll}
\hline No & \multicolumn{1}{c}{ Aktifitas } & \multicolumn{3}{c}{ Hasil Sebelumnya } & \multicolumn{3}{c}{ Kondisi Akhir saat ini } \\
& & \multicolumn{3}{c}{2018} & & & 2020 \\
& & & 10 & IP & 1 & 10 & IP \\
\cline { 3 - 8 } & & min & min & & min & min & \\
\hline 1 & Primary-Ground & 5190 & 8020 & 1,55 & 3530 & 4450 & 1,26 \\
\hline 2 & Sekundery- & 7100 & 11200 & 1,58 & 3960 & 6680 & 1,68 \\
& Ground & & & & & & \\
\hline 3 & Tertier-Ground & 7160 & 11900 & 1,66 & 4530 & 7670 & 1,69 \\
\hline 4 & Primary- & 6730 & 11900 & 1,77 & 3100 & 6110 & 1,97 \\
& sekundary & & & & & & \\
\hline 5 & Primary-tertier & 6460 & 12400 & 1,92 & 3580 & 6990 & 1,95 \\
\hline 6 & Sekundary- & 6480 & 12500 & 1,90 & 4960 & 9230 & 1,86 \\
& tertier & & & & & & \\
\hline
\end{tabular}

Cara pengujian dengan indeks polarisasi dilakukan dengan durasi waktu 10 menit lalu dibandingkan dengan hasil pengukuran isolasi pada satu menit pertama. Berdasarkan persamaan 2.1 maka indeks polarisasi dapat dihitung sebagai berikut:

Perhitungan indeks polarisasi pada primary-sekundary tahun 2018 :

$$
\begin{aligned}
I P & =\frac{11900}{6730} \\
& =1,77
\end{aligned}
$$

Perhitungan indeks polarisasi pada primary sekundary tahun 2020 :

$$
\begin{aligned}
I P & =\frac{6110}{3100} \\
& =1,97
\end{aligned}
$$

Dari hasil perhitungan yang dilakukan diatas maka pada belitan primary-sekundary tahun 2018 dan tahun 2020 masih dalam keadaan yang baik menurut aturan standar IEEE 43-2000.

\section{B. Hasil pengujian Tangen Delta}

Tangen delta adalah metode diagnostik kelistrikan untuk menentukan kondisi insulasi, trafo dianggap kapasitor murni. Kehilangan daya di delta tangen karena kapasitor tidak sempurna. Untuk mengetahui bahwa kondisi delta tangen masih baik maka perlu dilakukan perhitungan koreksi faktor daya, semakin kecil nilai delta tangen semakin baik. Jika nilai tangen delta tinggi maka kondisi tangen delta buruk.

Tabel 4. 1 data tahanan isolasi tangen delta tahun 2018

\begin{tabular}{|c|c|c|c|c|c|c|}
\hline $\begin{array}{l}\text { Peng } \\
\text { ukura } \\
\mathrm{n}\end{array}$ & $\begin{array}{l}\text { Test } \\
\mathrm{kV}\end{array}$ & $\mathrm{mA}$ & Watts & $\begin{array}{l}\mathrm{PF} \\
(\%)\end{array}$ & $\begin{array}{l}\text { Cor } \\
\mathrm{r} \\
\text { Fctr }\end{array}$ & $\begin{array}{l}\text { Cap } \\
(\mathrm{pF})\end{array}$ \\
\hline $\begin{array}{l}\mathrm{CHG} \\
+\mathrm{CH} \\
\mathrm{L} \\
\end{array}$ & 10,00 & $\begin{array}{l}32,8 \\
33\end{array}$ & $\begin{array}{l}0,61 \\
00\end{array}$ & 0,19 & $\begin{array}{l}0,8 \\
1\end{array}$ & $\begin{array}{l}10473, \\
74\end{array}$ \\
\hline $\mathrm{CHG}$ & 10,00 & $\begin{array}{l}11,3 \\
62 \\
\end{array}$ & $\begin{array}{l}0,29 \\
60 \\
\end{array}$ & 0,26 & $\begin{array}{l}0,8 \\
1 \\
\end{array}$ & $\begin{array}{l}3629,6 \\
9 \\
\end{array}$ \\
\hline $\mathrm{CHL}$ & 10,00 & $\begin{array}{l}21,5 \\
22 \\
\end{array}$ & $\begin{array}{l}0,31 \\
74 \\
\end{array}$ & 0,15 & $\begin{array}{l}0,8 \\
1 \\
\end{array}$ & $\begin{array}{l}6861,8 \\
3\end{array}$ \\
\hline $\begin{array}{l}\text { CLG } \\
+\mathrm{CL} \\
\mathrm{T}\end{array}$ & 10,00 & $\begin{array}{l}50,4 \\
30\end{array}$ & $\begin{array}{l}0,8 \\
723\end{array}$ & 0,17 & $\begin{array}{l}0,8 \\
1\end{array}$ & $\begin{array}{l}16069, \\
67\end{array}$ \\
\hline CLG & 10,00 & $\begin{array}{l}3,85 \\
9 \\
\end{array}$ & $\begin{array}{l}0,1 \\
424 \\
\end{array}$ & 0,37 & $\begin{array}{l}0,8 \\
1 \\
\end{array}$ & $\begin{array}{l}1229,1 \\
7 \\
\end{array}$ \\
\hline CLT & 10,00 & $\begin{array}{l}46,5 \\
59 \\
\end{array}$ & $\begin{array}{l}0,70 \\
50 \\
\end{array}$ & 0,15 & $\begin{array}{l}0,8 \\
1 \\
\end{array}$ & $\begin{array}{l}\text { 14871, } \\
11 \\
\end{array}$ \\
\hline $\begin{array}{l}\mathrm{CTG} \\
+\mathrm{CH} \\
\mathrm{T} \\
\end{array}$ & 5,00 & $\begin{array}{l}24,7 \\
09\end{array}$ & $\begin{array}{l}0,3 \\
592\end{array}$ & 0,29 & $\begin{array}{l}0,8 \\
1\end{array}$ & $\begin{array}{l}15766, \\
95\end{array}$ \\
\hline CTG & 5,00 & $\begin{array}{l}24,6 \\
43 \\
\end{array}$ & $\begin{array}{l}0,3 \\
599 \\
\end{array}$ & 0,29 & $\begin{array}{l}0,8 \\
1 \\
\end{array}$ & $\begin{array}{l}15689, \\
87\end{array}$ \\
\hline CHT & 3,00 & $\begin{array}{l}0,12 \\
6\end{array}$ & $\begin{array}{l}- \\
0,0 \\
006\end{array}$ & $-0,07$ & $\begin{array}{l}0,8 \\
1\end{array}$ & 80,52 \\
\hline
\end{tabular}

\begin{tabular}{lllllll}
\hline $\begin{array}{l}\text { Pengukur } \\
\text { an }\end{array}$ & $\begin{array}{l}\text { Test } \\
\mathrm{kV}\end{array}$ & $\mathrm{Ma}$ & $\begin{array}{l}\text { Watt } \\
\mathrm{s}\end{array}$ & $\begin{array}{l}\mathrm{PF} \\
(\%\end{array}$ & $\begin{array}{l}\text { Co } \\
\mathrm{rr}\end{array}$ & $\begin{array}{l}\text { Cap } \\
(\mathrm{pF})\end{array}$ \\
& & & & $\begin{array}{l}\text { Fct } \\
\mathrm{r}\end{array}$ & \\
\hline CHG+C & 10,0 & 32,8 & 0,536 & 0,1 & 0,8 & 10468, \\
HL & 0 & 67 & 4 & 6 & 1 & 97 \\
\hline CHG & 10,0 & 11,3 & 0,209 & 0,1 & 0,8 & 3621,3 \\
& 0 & 40 & 6 & 9 & 1 & 9 \\
\hline CHL & 10,0 & 21,5 & 0,312 & 0,1 & 0,8 & 6864,4 \\
& 0 & 49 & 8 & 5 & 1 & 0 \\
\hline
\end{tabular}

\begin{tabular}{lllllll}
\hline CLG+CL & 10,0 & 50,4 & 0,84 & 0,1 & 0,8 & 16069, \\
T & 0 & 27 & 73 & 7 & 1 & 47 \\
\hline CLG & 10,0 & 3,85 & 0,13 & 0,3 & 0,8 & 1229,0 \\
& 0 & 7 & 65 & 6 & 1 & 1 \\
\hline CLT & 10,0 & 46,7 & 0,720 & 0,1 & 0,8 & 14871, \\
& 0 & 08 & 8 & 5 & 1 & 34 \\
\hline CTG+C & 5,00 & 24,7 & 0,36 & 0,2 & 0,8 & 15771, \\
HT & & 36 & 29 & 9 & 1 & 83 \\
\hline CTG & 5,00 & 24,6 & 0,36 & 0,3 & 0,8 & 15694, \\
& & 45 & 32 & 0 & 1 & 15 \\
\hline CHT & 3,00 & 0,07 & 0,00 & 0,2 & 0,8 & 80,44 \\
& & 6 & 05 & 3 & 1 & \\
\hline
\end{tabular}

Tabel 4.3 data tahanan isolasi tangen delta tahun 2020

Berdasarkan persamaan 2.11 maka tangen delta dapat dihitung sebagai berikut:

Perhitungan hasil pengujian tangen delta tahun 2018 di Gardu induk $150 \mathrm{kV}$ Kebasen Tegal pada tabel diatas $\mathrm{CHG}+\mathrm{CHL}$ :

Diketahui :

P : 0,5364 Watt

V : 10000 Volt

C : $10468,97 \times 10^{-12} \mathrm{~F}$

$\omega: 2 \pi f$

$$
\begin{gathered}
\operatorname{Tan} \delta=\frac{0,5364}{10000^{2} \times 2 \times 3,14 \times 50 \times 10468,97 \times 10^{-12}} \\
\times 100 \% \\
=0,16 \%
\end{gathered}
$$

Perhitungan hasil pengujian tangen delta tahun 2020 di Gardu induk $150 \mathrm{Kv}$ Kebasen Tegal pada tabel diatas $\mathrm{CHG}+\mathrm{CHL}$ :

Diketahui :

$\mathrm{P}: 0,6100 \mathrm{Watt}$

$\mathrm{V}: 10000$ Volt

$\mathrm{C}: 10473,74 \times 10^{-12} \mathrm{~F}$ 


$$
\begin{gathered}
\omega: 2 \pi f \\
\operatorname{Tan} \delta=\frac{0,6100}{10000^{2} \times 2 \times 3,14 \times 50 \times 10473,74 \times 10^{-12}} \\
\times 100 \% \\
=0,19 \%
\end{gathered}
$$

Dari perhitungan yang telah dilakukan pada bagian $\mathrm{CHG}+\mathrm{CHL}$ tahun 2018 dan tahun 2020 maka dapat dikatakan bahwa kondisi tangen delta nya dalam keadaan yang baik yaitu dibawah $0,5 \%$, menurut ANSI C 57.12.90.

\section{Hasil Pengujian Minyak}

Pengujian kualitas pada minyak trafo berguna untuk menilai keadaan minyak trafo yang digunakan untuk mengisolasi tegangan. Umur pada transformator ditentukan oleh keadaan dari sistem diisolasinya, dan hasil pengujian bisa digunakan untuk mengetahui kondisi dari tranformator.

\begin{tabular}{|c|c|c|c|c|c|c|c|c|}
\hline \multirow[t]{2}{*}{$\begin{array}{l}\mathrm{N} \\
\mathrm{O}\end{array}$} & $\begin{array}{c}\text { Uraian } \\
\text { Kegiat } \\
\text { an }\end{array}$ & \multicolumn{6}{|c|}{$\begin{array}{l}\text { Hasil } \\
\text { Pengujian } \\
(\mathrm{kV})\end{array}$} & \multirow[t]{2}{*}{$\begin{array}{c}\text { Rat } \\
\text { a- } \\
\text { rata }\end{array}$} \\
\hline & $\begin{array}{l}\text { Test } \\
\text { suhu } \\
: 36^{\mathrm{O}}\end{array}$ & 1 & 2 & 3 & 4 & 5 & 6 & \\
\hline 1 & $\begin{array}{c}\text { Minya } \\
\text { k } \\
\text { Bawa } \\
\text { h }\end{array}$ & $\begin{array}{r}69 \\
, 7\end{array}$ & $\begin{array}{c}71 \\
, 5\end{array}$ & $\begin{array}{l}70 \\
, 2\end{array}$ & $\begin{array}{c}69 \\
9\end{array}$ & $\begin{array}{c}65, \\
1\end{array}$ & $\begin{array}{c}73 \\
, 2\end{array}$ & $\begin{array}{c}69 \\
9\end{array}$ \\
\hline 2 & $\begin{array}{c}\text { Minya } \\
k \\
\text { OLTC }\end{array}$ & $\begin{array}{c}32 \\
, 6\end{array}$ & $\begin{array}{c}50 \\
, 8\end{array}$ & $\begin{array}{r}56 \\
, 6\end{array}$ & $\begin{array}{c}58, \\
7\end{array}$ & $\begin{array}{c}59, \\
7\end{array}$ & $\begin{array}{r}61 \\
, 6\end{array}$ & $\begin{array}{c}53 \\
3\end{array}$ \\
\hline
\end{tabular}

Tabel 4. 2 data hasil pengujian minyak trafo

Berdasarkan persamaan 2.12 maka kekuatan dielektrik minyak dapat dihitung sebagai berikut

Perhitungan kekuatan dielektrik minyak pada transformator 4 menggunakan rumus berikut :

Diketahui :

$\mathrm{Vb}$ rata-rata $=69,9 \mathrm{kV}$

$$
\mathrm{d}=2,5 \mathrm{~mm}
$$

minyak bawah : $\quad$ Erata - rata $=\frac{69,9}{2,5}$

$$
=27,96
$$

$(\mathrm{kV} / \mathrm{mm})$

Diketahui :

$\mathrm{Vb}$ rata-rata $=53,3 \mathrm{kV}$

$$
\mathrm{d}=2,5 \mathrm{~mm}
$$

Minyak OLTC : $\quad$ rata - rata $=\frac{53,3}{2,5}$

$=21,32(\mathrm{kV} / \mathrm{mm})$

Pada perhitungan diatas didapat nilai untuk kekuatan dielektrik minyak bawah sebesar 27,96 (kV /mm) dan kekuatan dielektrik minyak oltc sebesar $21,32(\mathrm{kV}$ /mm).
D. Analisis hasil pengujian indeks polarisasi

\section{Pengujian indeks polarisasi GI 150 kV Tegal}

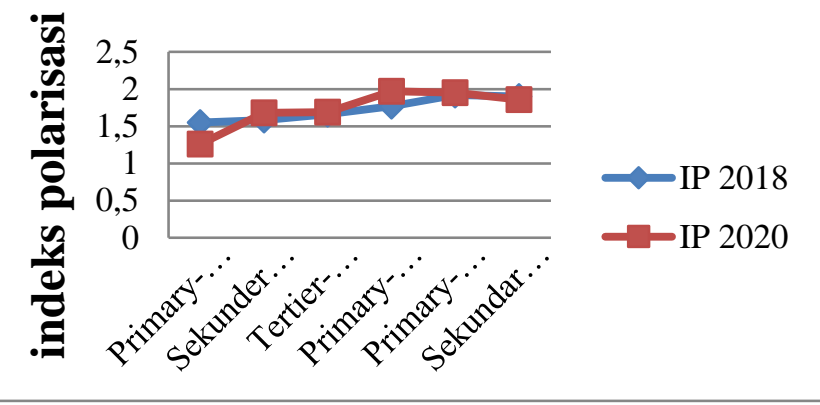

Grafik 4. 1 hasil pengujian indeks polarisasi

Dari hasil perhitungan indeks polarisasi berdasarkan tabel 4.1 didapatkan hasil pada transformator bay 460 Mva di gardu induk $150 \mathrm{kV}$ Tegal pada tahun 2018 dan 2020 rata-rata masih dalam keadaan baik. Pada bagian primary-ground nilai indeks polarisasi mengalami penuruan yang signifikan sebesar 0,29 dibandingkan bagian-bagian lain. Untuk nilai indeks polarisasi paling rendah yaitu sebesar 1,26 dibagian primary-ground mendekati batas dikatakan baik menurut IEEE yaitu sebesar 1,25. Oleh karena itu untuk menghindari hal-hal yang tidak diinginkan maka perlu ditindak lanjuti dibagian tersebut yaitu dilakukan pengecekan lilitan apakah ada yang bermasalah seperti kotor ataupun lembab. Jika kita lihat pada grafik diatas maka nilai indeks polarisasi pada tahun 2018 dan 2020 dalam keadaan yang baik yaitu diatas 1,25 sehingga dapat disimpulkan bahwa transformator bay 4 memenuhi standar yang digunakan oleh IEEE sehingga pengoperasian dari transformator aman untuk diberikan tegangan dan juga terhindar dari kegagalan isolasi.

\section{E. Analisis hasil pengujian tangen delta}

\section{Pengujian tangen delta GI 150 kV Tegal}

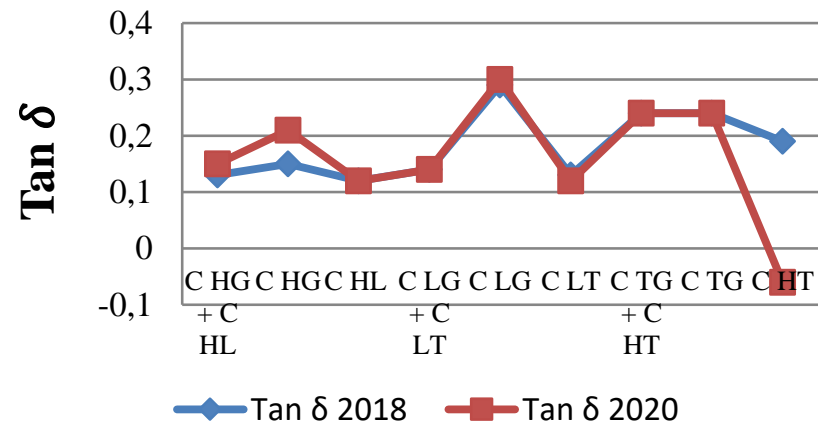

Grafik 4. 2 hasil pengujian tangen delta 
Dari hasil perhitungan nilai tangen delta berdasarkan tabel 4.2 didapatkan hasil pada transformator bay 460 Mva di gardu induk $150 \mathrm{kV}$ Tegal pada tahun 2018 dan 2020 rata-rata masih dalam keadaan baik yaitu dibawah $0,5 \%$ sesuai dengan standar yang diizinkan menurut ANSI C 57.12.90. Dan juga hasil pengujian di tahun 2018 dan 2020 tidak terjadi perubahan nilai yang siginifikan. hanya dibagian CHG mengalami kenaikan yaitu pada tahun 2018 sebesar 0,19\% menjadi 0,26\% dan pada bagian CHT mengalami penurunan yang cukup signifikan yaitu pada tahun 2018 sebesar $0,23 \%$ menjadi $-0,07 \%$. Hasil tangen delta pada mode CHT nilainya adalah $-0,07 \%$ hal ini bisa terjadi dikarenakan kontaminasi atau akibat dari arus bocor pada isolasi kumparan transformator, sehingga perlu ditindak lanjuti agar tidak terjadi pemburukan pada pengujian lainnya. Karena nilai tangen delta yang baik adalah dibawah 0,5 $\%$ menurut standar ANSI C 57.12.90

\section{F. Analisis pengujian breakdown voltage}

\section{Pengujian breakdown voltage GI $150 \mathrm{Kv}$ Tegal}

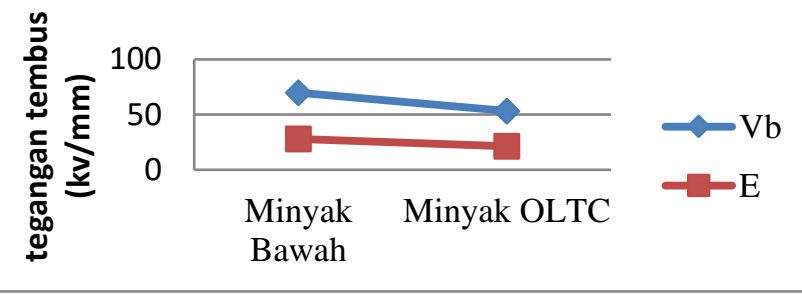

Grafik 4. 3 pengujian breakdown voltage

Dari hasil pengujian breakdown voltage berdasarkan tabel 4.4 didapatkan hasil pada transformator bay 460 Mva di gardu induk $150 \mathrm{kV}$ Tegal pada tahun 2020 diatas $50 \mathrm{kV}$ semua baik dari minyak bawah nilainya sebesar 69,9 kV maupun dari minyak OLTC nilainya sebesar 53,3 kV. Menurut aturan standar IEC 60156 nilai tegangan tembus dikatakan baik apabila nilainya diatas $50 \mathrm{kV}$. Dari hasil diatas menunjukan bahwa minyak pada transformator masih dalam keadaan baik dan layak digunakan. Dan untuk nilai kekuatan dielektrik pada minyak bawah sebesar $27,96 \mathrm{kV} / \mathrm{mm}$ dan minyak oltc sebesar $21,32 \mathrm{kV} / \mathrm{mm}$. semakin besar nilai tegangan tembus dari hasil yang diuji maka nilai kekuatan dielektrik atau ketahanan isolasinya semakin bagus. Jadi bisa dikatakan bahwa nilai tegangan tembus berbanding lurus dengan kekuatan dielektrik atau ketahanan isolasi.

\section{KESIMPULAN}

Dari hasil perhitungan dan analisa yang telah dilakukan dalam analisis tahanan isolasi pada transformator tenaga dengan menggunakan indeks polarisasi, tangen delta dan breakdown voltage di gardu induk $150 \mathrm{kV}$ kebasen Tegal maka dapat diambil kesimpulan sebagai berikut:

1. Berdasarkan hasil perhitungan nilai indeks polarisasi (IP) diperoleh hasil nilai disemua belitan dengan nilai terendah 1,26 dan nilai tertinggi 1,97 sesuai dengan standar IEEE 43-2000 dikatakan bahwa transformator dalam keadaan baik jika nilai IP berkisar anatara 1,25-2. Menunjukan transformator masih dalam keadaan baik.

2. Berdasarkan hasil pengujian tangen delta di transformator bay 4 rata-rata dalam keadaan yang baik yaitu dibawah $0,5 \%$ hanya dibagian mode CHT mengalami pemburukan sebesar $-0,07 \%$.

3. Berdasarkan hasil pengujian minyak trafo untuk minyak bawah menghasilkan nilai rata-rata sebesar $69,9 \mathrm{kV}$ dan minyak OLTC dengan nilai rata-rata sebesar 53,3 kV menunjukan bahwa keduanya masih dalam keadaan baik dan tidak perlu pergantian minyak.

4. Dari hasil pengujian yang telah dilakukan maka transformator tenaga 60 MVA bay 4 di gardu induk $150 \mathrm{kV}$ Kebasen Tegal masih dalam keadaan yang baik dan masih layak untuk dioperasikan.

\section{Daftar Pustaka}

[1] F. Nanda, "Peningkatan Kualitas dan Karakterisasi Transformator Step up Satu Fasa 250 VA , 10 kV , 50 $\mathrm{Hz}, ” 2018$.

[2] M. Fajar, "Analisis Kondisi Hasil Pengujian Transformator III 150/20kV 16MVA GI Jajar Dalam Keadaan padam," J. Linguist., vol. 3, no. 2, pp. 139157, 2018.

[3] Muhammad syahendra Anindyantoro, "Analisa tahanan isolasi pada transformator tenaga di gardu induk wonogiri," 2017.

[4] Tomy Adi Saputro, "Analisis hasil pengujian tahanan isolasi transformator daya." .

[5] Dwi Ari Wibowo, "Analisa pengujian isolasi transformator daya 60 MVA Pada gardu induk jajar,"

[6] I. Std, I. Power, E. Society, and I. S. Board, "IEEE Recommended Practice for Testing Insulation Resistance of Electric Machinery IEEE Power and Energy Society,” vol. 2000, pp. 9-14, 2013.

[7] Baddarudin, "Analisa minyak transformator pada transformator 3 fasa di PT SASINDO," vol. 6, no. 2, p. 103, 2018.

[8] "Pengujian tangen delta trafo dan bushing kasuskhusus tangen delta negatif oleh Arief Setyowibowo.".

[9] P. Persero, "Pengukuran data teknik," p. 380366, 2010. 